\title{
DECISION MAKING BY EXTRACTING SOFT INFORMATION FROM CSR NEWS REPORT
}

\author{
Sin-Jin LIN ${ }^{1}$, Ming-Fu HSU² ${ }^{\star}$ \\ ${ }^{1}$ Department of Accounting, Chinese Culture University, 55, Hwa-Kang Rd., \\ Yang-Ming-Shan, Taipei, Taiwan \\ ${ }^{2}$ English Program of Global Business, Chinese Culture University, 55, Hwa-Kang Rd., \\ Yang-Ming-Shan, Taipei, Taiwan
}

Received 16 May 2017; accepted 31 March 2018

\begin{abstract}
This study examines the impact of corporate social responsibility (CSR) news reports on corporate operating performance forecasting using a large database of publicly-listed electronics firms in Taiwan. Applying text mining techniques and latent topic modelling, we construct and measure the intensity of the CSR-corpus index (ICSRI), which can compress tremendous amounts of CSR textual information content into synthesized meaningful dimensions. By doing so, we are able to break down CSR news reports into multiple dimensions and then examine which dimension(s) affects operating performance. To offer decision-makers with a comprehensive, overarching view of the corporate's operations, this study incorporates balanced scorecards (BSC) and multiple criteria decision analysis (MCDA) to form a final performance rank. The proposed approach, supported by real samples, can assist both internal and external stakeholders in allocating scarce resources to specific CSR dimensions to enhance a corporate's growth potential as well as to achieve a win-win situation.
\end{abstract}

Keywords: corporate social responsibility, multiple criteria decision analysis, text mining, topic modelling, decision making.

JEL Classification: C63, C81, D81, M14, M41.

\section{Introduction}

The global financial tsunami that followed the Lehman Brothers' bankruptcy had a tremendous effect on most countries and focused the attention of policy makers on the real economic consequences of such events (Chong, Wang, Gladys, \& Cheong, 2014). Following a financial crisis/distress, countries usually encounter harsh economic turbulence and a severe recession. Bohl, Michaelis, and Siklos (2016) stated that global financial crises result in a general negative real per capita GDP growth around the world, impedes the circulation of

${ }^{*}$ Corresponding author. E-mail: hsumf0222@gmail.com

This is an Open Access article distributed under the terms of the Creative Commons Attribution License (http://creativecommons. org/licenses/by/4.0/), which permits unrestricted use, distribution, and reproduction in any medium, provided the original author and source are credited. 
economic resources, and negatively impacts stock markets' development. At the micro-level, a corporate financial crisis typically refers to when a firm has a net operating loss, fails to pay debts, or violates regulations or laws (Hyun, 2016; Mollah, Quoreshi, \& Zafirov, 2016). While various countries have dissimilar accounting principles and rules, and the definition of a financial crisis is not always the same, it is widely agreed that a financial crisis results in the tremendous weakening of corporates' profitability over time. If a pre-warning system on financial crisis detection is trustful and reliable, then top executives can initiate remedial treatment to prevent the crisis from bursting forth, and investors can grasp any profitability situation that may arise and modify their investment strategies to maximize their personnel wealth under anticipated risk exposure scenarios (Geng, Bose, \& Chen, 2015). Thus, detecting early signs of financial vulnerability turns out to be an increasingly urgent task (Buncic \& Piras, 2016).

The efforts towards identifying a corporate financial crisis began with the $\mathrm{z}$-score, which is grounded on the implementation of the accounting-based ratios of Beaver (1996) for use in the multiple discriminant analysis (MDA) of Altman (1968). Zmijewski (1984), Jones (1987), and Pantalone and Platt (1987) provided other essential related works on financial crisis detection through their usage of logit and probit models. Compared to such literature on financial crisis or failure prediction, research studies building up a corporate operating performance assessment model are rather limited, even as such an assessment could widely help to discover the inevitable/irreversible pre-stage that leads up to the financial crisis. The main cause of a financial crisis is bad management, and corporate operating performance is a reliable proxy for corporate management (Xu \& Wang, 2009; Asmild \& Zhu, 2016).

A considerable amount of researchers and top executives in recent years have devoted tremendous resources and time to investigating the impact of corporate social responsibility (CSR) on corporate operating performance. CSR considers the voluntary integration of social and environmental concerns in a corporate's operations and in its interaction with stakeholders (Commission of the European Communities, 2001), turning it into one of the most attractive topics of the global economy (Isaksson \& Steimle, 2009; Crifo, Diaye, \& Pekovic, 2016; Zhu, Liu, \& Lai, 2016). Although there are various definitions and dimensions of CSR in the extant context, Carroll's $(1979,1991,1998)$ definition with four CSR dimensions has been widely utilized: a corporate should (1) comply with laws and regulations announced by public sectors or governments in its operations, (2) meet stakeholders' expectations and protect them regardless if these activities are not codified into law, (3) make goods or services for buyers to gain appropriate profitability in the process, and (4) meet stakeholders' expectations in the corporate's engagement of strengthening and increasing human welfare or firm reputation. Mohr, Webb, and Harris (2001) further deemed CSR as a corporate's commitment to eliminating or minimizing any harmful effects and maximizing its long-run helpful impact on society.

From the above viewpoints, CSR encompasses numerous actions, such as environmental protection, ethical behavior, and fair treatment of employees. Moreover, CSR may function similarly to advertising, by increasing demand for products and services, reducing consumer price sensitivity (Navarro, 1988; Sen \& Bhattacharya, 2001; Cheng, Ioannou, \& Serafeim, 2014; Fatma, Rahman, \& Khan, 2016; Fatma \& Rahman, 2016), facilitating corporates to 
establish intangible assets (Hull \& Rothenberg, 2008), mitigating the likelihood of legislative procedure (Freeman, 1984), increasing the buying intention of socially conscious consumers (Hillman \& Keim, 2001), and attracting economic resources from socially responsible investors (Kapstein, 2001). However, even if several studies conclude that the relationship between corporate operating performance and CSR is positive, there is no concrete consensus so far (Crifo et al., 2016).

One of the possible reasons for not reaching unanimity comes from the effect of the quality-quantity trade-off among each one of the CSR dimensions (Cavaco \& Crifo, 2014). A corporate's CSR strategy is multi-dimensional, encompassing environmental, business, and social behaviors. Consequently, implementing a singular item as a proxy to represent the corporate's CSR status would mislead the research outcome about the relationship between CSR and operating performance (Surroca, Tribo, \& Waddock, 2010) - that is, some forms of socially responsible behaviors have positive impacts on corporate operating performance while others do not. Therefore, there is an urgent requirement to break down CSR among the multiple dimensions in order to examine its potential impact on corporate operating performance (Barcos, Barroso, Surroca, \& Tribó, 2013; Crifo et al., 2016).

To construct these measures (i.e., divide the synthesized CSR status into numerous aspects), this study performs an advanced latent topic technique, latent Dirichlet allocation (LDA), on information retrieval categories. It is a robust technique that relies on statistical correlations among words in a large set of documents to identify the informative topics (Blei, Ng, \& Jordan, 2003; Barnard et al., 2003). By implementing LDA on CSR news reports, we can extract the informative and interpretable topics/dimensions and then examine the effectiveness of each topic/dimension on corporate operating performance.

A great proportion of extant studies evaluating corporate operating performance employs accounting-based measures, such as return on investment (ROI), return on assets (ROA), and return on sales (ROS) (Magni, 2015; Rodriguez-Fernandez, 2016), but these assessing criteria are considered to be quantitative-based measures, sometimes making it complicated to estimate and reliably depict the whole facet of a corporate's operating status in a highly competitive environment. To overcome this weakness, the present study employs a strategic planning and management system, balanced scorecards (BSC), which can add qualitativebased performance measures (i.e., non-monetary-based measures) to conventional quantitative-based measures (i.e., monetary-based measures) in order to provide decision-makers or top executives with a much more "balanced" aspect of a corporate's operating performance (Kaplan \& Norton, 1992; Grigoroudis, Orfanoudaki, \& Zopounidis, 2012). This system not only conducts the task of performance measurement, but also gives directions for planners to identify what should be done and what should be measured, consequently enabling executives to truly fulfill their goals and purposes (Kaplan \& Norton, 1993). Although BSC has demonstrated its usefulness and effectiveness, it still exhibits some weaknesses, such as it often appears too general, and hence decision-makers may have trouble on how to implement it on a daily basis, or the quantitative-based measure is incapable of representing or portraying the corporate's purpose and strategy (Malmi, 2001). To handle BSC's multi-dimensional problem, this study implements the simple multi-attribute rating technique exploiting ranks (SMARTER), which is a kind of multiple-criteria decision analysis (MCDA) technique. By 
integrating BSC and MCDA, the model can represent the preference system of the corporate's management under a minimum information requirement and thus determine the corporate's operating performance in a more reliable way.

We feed the multiple considerations derived from CSR news reports by LDA and the operating performance status determined by BSC+MCDA into the kernel-based model to construct the forecasting mechanism. SVM, grounded on structural risk minimization (SRM), has gained a great deal of attention due to its outstanding forecasting performance and has been successfully implemented in a variety of real-life problems. However, the superior forecasting performance of SVM comes with a critical weakness - it lacks computational efficiency (Kumar \& Gopal, 2009; Kumar, Khemchandani, Gopal, \& Chandra, 2010). In brief, it has to handle the quadratic programming problem (QPP) in the training stage, which restricts the usage of SVM to large-scale tasks. To address this obstacle, many improved methods, such as Chunking, SMO, SVMLight, etc., have been introduced to efficiently resolve the optimization tasks embedded in the original SVM.

Another way to facilitate the calculation speed of SVM is to modify the inherent structure of SVM, such as with Generalized Eigenvalue Proximal SVM (GEPSVM) and Twin SVM (TSVM) (Shao \& Deng, 2012; Shao, Chen, Wang, Li, \& Deng, 2015). GEPSVM aims at constructing two non-parallel decision surfaces, such that each decision surface is closer to its class and is as far away as possible from the other class. Jayadeva, Khemchandani, and Chandra (2007) set up Twin SVM (TSVM), one of the variants of GEPSVM, which aims at solving a pair of relatively reduced QPPs, instead of a large one in the traditional SVM (Shao, Zhang, Wang, \& Deng, 2011). Thus, TSVM can finish the calculation performance about four times faster than the traditional SVM (Jayadeva et al., 2007). Chen, Yang, Ye, and Liang (2011) subsequently introduced a more sophisticated TSVM-based technique, Projection Twin SVM (PTSVM), which preserves the merit of TSVM (it is executed by solving two reduced QPPs) and strengthens TSVM's forecasting quality by obtaining two projection directions (Shao, Wang, Chen, \& Deng, 2013; Ding \& Hua, 2014). Its superior performance has been proven in numerous experimental implementations. To our knowledge, the literature has not yet constructed a forecasting architecture for corporate operating performance that simultaneously integrates multiple dimensions of CSR news reports derived from LDA and PTSVM. To fill this gap, we combine multiple dimensions of CSR news reports and financial information content and feed them into PTSVM to construct an emerging forecasting architecture. The main contributions of this study are summarized as follows.

- We propose a reliable method for corporate operating performance assessment by integrating BSC and MCDA. Apart from previous related works that merely implement a monetary-based measure to form a final decision, the proposed model can handle monetary-based and non-monetary-based measures at the same time and further incorporates MCDA to provide a more thorough description of a corporate's operating status.

- We propose an emerging approach to breaking down CSR news reports into multiple dimensions by LDA and preserve those dimensions that are highly related to corporate operating performance.

- This study introduces an emerging architecture to assess corporate operating performance, which can help at discovering a potential financial crisis before it erupts. 
- The introduced hybrid model, which is supported by a real case targeting the electronics industry in Taiwan, can assist both internal and external market participants who must allocate their personnel wealth while forming their own investment strategies.

The remainder of this study is organized as follows. Research design briefly describes the proposed model. Practical examination depicts the details of the research design and practical results. Finally, conclusions and managerial implication summarizes the conclusion of the present work and provides some direction for future works.

\section{Research designs}

\subsection{Corporate's CSR performance determination and CSR-related corpus construction}

Due to the nature of CSR's multi-dimensional facets, such as human rights, environment, community, employee relations, corporate governance, and business behaviors toward customers and suppliers, the determination of a corporate's CSR performance is a challenging and critical task (Crifo et al., 2016; Fatma \& Rahman, 2016; Fatma et al., 2016). To overcome this obstacle and offer decision makers a thorough assessment on CSR, Global Views, which is one of Taiwan's most prestigious publishing groups, takes the Principle of ISO 26000 Social Responsibility (International Organization for Standardization) when it issues its Corporate Social Responsibility Award based on 7 core subjects: organization governance, consumer issues, community involvement and development, human rights, labor practices, environment, and fair operating practices. If a firm receives this Corporate Social Responsibility Award, then it is designated as exhibiting superior CSR performance. If a firm does not receive the award and violates the CSR rules, then it can be deemed as exhibiting inferior CSR performance. Based on this definition, we divide corporates into two different groups: Good CSR category and Bad CSR category.

$\mathrm{Li}$ (2010) indicated that financial reports contain a large amount of optimistic terms that could represent a firm's chances for gaining greater profit in the following years. They also have longer earning persistence than a corporate's reports that are full of pessimistic terms. We note that the terms in two dissimilar categories (i.e., crisis vs. non-crisis or good CSR vs. bad CSR) are quite different. Grounded on previous research findings, this study looks to construct a well-structured CSR corpus that can help decision makers to easily stay abreast of recent changes in CSR terminology as well as provide them a suitable way for information retrieval. How to systematically distinguish representative special terms between good CSR category and bad CSR category is thus an urgent task.

The Chi-square test, which evaluates whether the terms in different categories are independent or correlated, can be compared to a Chi-square distribution with one degree of freedom so as to judge the level of extremeness (Crouch \& Yang, 1992). Through this we can identify the selected special terms for a specific category (i.e., good CSR and bad CSR). How to determine the strength of each term is another important issue, as the special terms within each specific category could transmit different levels of decision information. We hence perform the entropy method, which has been successfully executed in computational linguistic analysis as a measure of the relative weights among all special terms, to solve this problem. After finishing all the processes, the CSR corpus can be constructed (see Table 1). 
Table 1. The partial CSR corpus

\begin{tabular}{|l|c|l|c|}
\hline \multicolumn{1}{|c|}{ Terms for superior CSR status } & Weight & \multicolumn{1}{c|}{ Terms for inferior CSR status } & Weight \\
\hline Healthy & 0.090 & Loss & 0.083 \\
\hline Continue & 0.071 & Affection & 0.067 \\
\hline Responsibility & 0.064 & Decrease & 0.058 \\
\hline Environmental protection & 0.055 & Casualties & 0.057 \\
\hline Development & 0.051 & Deficiency & 0.052 \\
\hline Assure & 0.042 & Malpractice & 0.048 \\
\hline Promotion & 0.040 & Shock & 0.043 \\
\hline Goal & 0.040 & Modification & 0.037 \\
\hline Operation & 0.039 & Reduce & 0.030 \\
\hline Performance & 0.037 & Lay off & 0.027 \\
\hline Sustainability & 0.032 & Severance & 0.020 \\
\hline Active & 0.028 & Indemnification & 0.018 \\
\hline Efficiency & 0.021 & Illegal & 0.015 \\
\hline Energy saving & 0.019 & Risk & 0.011 \\
\hline Creativity & 0.013 & Bias & 0.006 \\
\hline
\end{tabular}

\subsection{Quantify News media information}

Numerical information depicts a corporate's past performance is not the only source for decision makers to reach a final judgment in today's information explosive environment. On the contrary, most decision makers like to make their decisions based on the acquisition of public information from various media outlets. The fundamental rationale is that the signal for a change in a corporate's financial situation may likely appear in textual information earlier than if one tries to identify potential negative changes just through financial numbers (Shirata, Cindy, Takeuchi, Ogino, \& Watanabe, 2011). However, the information provided by these various sources will often contain tremendous essential message, if such message is unstructured and not appropriated handled, then huge amount of valuable message will turn out to be useless and redundant. Thus, how to handle the large amount of unstructured or semi-structured textual information is an attractive research topic in a big data environment. Furthermore, not all of the collected news is CSR-related and most CSR-related news contains more than one topic/dimension. Thus, this study merely considers the CSR-related news reports so as to prevent it from reaching a biased conclusion and subsequently conducts LDA to break down CSR news reports into multiple dimensions/topics and match the dimensions/topics with pre-decided CSR-corpus to condense the tremendous textual information content into synthesized indicators. By doing so, we can examine the impact of each CSRdimension derived from CSR news reports on corporate operating performance forecasting. For example, the CSR-related news contains some dimensions/topics decided by LDA, and each dimension contains some essential terms. Sequentially, we match the term in each dimension with CSR-corpus. Due to each term in CSR-corpus have different weights, we can aggregate the weight in each dimension to determine the final condensed outcome. By doing so, we can transform the textual information into numerical information as well as give decision makers more supplementary information beyond what the numerical information offers. 


\section{Practical examinations}

\subsection{The research samples}

The electronics industry is one of the most attractive research samples among all the capitalintensive industries in Taiwan. This specific industry not only has a considerable impact on the global supply chain, but also has become an essential capital market to international investors as well. Furthermore, Taiwan's government has provided numerous investment incentives and financing policies and has invested large amounts of resources into this industry, turning it into an economic backbone of the domestic stock market. In particular, its stock transactions make up over $70 \%$ of the Taiwan stock market turnover. Thus, we choose this specific industry as our research target, with the data collected from public websites, such as Taiwan Economic Journal data bank (TEJ), Taiwan Stock Exchange Corporation (TSEC), and Taipei Exchange (TE) from the period 2014-2015.

\subsection{The features}

Corporate operating performance measurement is highly related to the topic of financial crisis detection, whereby the chosen features are conducted as the surrogate for joining up with the condition features. The condition features used in this study were gathered from two main sources: (1) financial reports and (2) CSR news reports. The financial ratios used in this study were F1: NI/TA (Net income to total assets), F2: WC/TA(Working capital to total assets), F3: TL/TA(Total liabilities to total assets), F4: NI/(TA-TL)(Net income to (total assets-total liabilities)), F5: COGS/I(Cost of goods sold to inventory), F6: FA/TA(Fixed assets to total assets), F7: S/TA(Sales to total assets), F8: RE/TA(Retained earnings to total assets), F9: TL/ TE(Total liabilities to total equities), and F10: LTL/TA(Long-term liabilities to total assets).

To quantify the textual information from CSR news reports, we have to go through two procedures: (1) establish the CSR-related corpus and (2) determine intensity CSR-performance indices (ICSRPIs). We gather the CSR reports from both categories (corporates with good and bad CSR status) and execute Chi-square to extract the representative special terms from both categories. Subsequently, entropy is performed to determine the relative weights among all special terms. After finishing the whole process, the CSR corpus can be reached.

To sequentially quantify the instant and relevant information of the textual content from CSR news reports, this study conducts LDA. LDA can identify the latent topics/dimensions hidden in the CSR news reports (that is, it breaks down the CSR news report into numerous dimensions/topics), each topic/dimension is matched with the CSR-related corpus, and then it aggregates the outcome to generate ICSRPIs. In total, we collected around 3000 news items from Yahoo!Kimo for the period 2014-2015. Due to the merits of collapsed Gibbs sampling (Griffiths \& Steyvers, 2004), such as quick convergence to the stationary states and reaches superior performance, it was taken to deal with the inference task and extract the latent topics in LDA. Deleting the non-informative topics by users, only four main topics/dimensions: (1) ICSRPI Environment-Business behaviors (ICSRI-EB), (2) ICSRPI Product-Business behaviors (ICSRPI-PB), (3) ICSRPI Customer-Supplier behaviors (ICSRPI-CS), and (4) ICSRPI Community-Business behaviors (ICSRPI-CB), were taken into consideration. Table 2 lists the descriptive statistics of each condition's features. 
Table 2. The descriptive statistics of each condition features

\begin{tabular}{|l|c|c|c|c|}
\hline \multicolumn{1}{|c|}{ Condition features } & Max. & Min. & Mean & S. D. \\
\hline F1: NI/TA & 0.403 & -0.438 & 0.055 & 0.089 \\
\hline F2: WC/TA & 0.889 & -0.242 & 0.300 & 0.199 \\
\hline F3: TL/TA & 0.877 & 0.077 & 0.415 & 0.167 \\
\hline F4: NI/(TA-TL) & 0.597 & -2.813 & 0.082 & 0.230 \\
\hline F5: COGS/I & 57.75 & 1.060 & 7.491 & 6.108 \\
\hline F6: FA/TA & 0.715 & 0.003 & 0.253 & 0.163 \\
\hline F7: S/TA & 5.720 & 0.160 & 0.977 & 0.643 \\
\hline F8: RE/TA & 0.642 & -2.351 & 0.082 & 0.226 \\
\hline F9: TL/TE & 7.116 & 0.083 & 0.911 & 0.838 \\
\hline F10: LTL/TA & 0.637 & 0.000 & 0.062 & 0.086 \\
\hline T1: ICSRI-EB & 5.423 & 0.009 & 0.366 & 0.658 \\
\hline T2: ICSRPI-PB & 1.340 & 0.002 & 0.090 & 0.163 \\
\hline T3: ICSRPI-CS & 6.902 & -0.382 & 0.044 & 0.958 \\
\hline T4: ICSRPI-CB & 7.700 & -0.426 & 0.049 & 1.068 \\
\hline
\end{tabular}

Notes: ${ }^{\text {Max.: }}$ maximum; Min.: minimum; S.D.: standard deviation.

\subsection{Determining a corporate's operating performance status and the forecasting model's assessing criteria}

Kaplan and Norton (1992) stated that a corporate relying mainly on monetary-based measures to determine its operating performance is inadequate in a complex and constantly changing atmosphere, as well as it also neglects the influence of intangible assets (such as internal business improvement, customer satisfaction, and the ability of the firm to learn and innovate) on the corporate's operating performance. Thus, there is an urgent requirement to develop a model that includes a wide range of more generic measures that are capable of linking long-term financial success to performance achieved from the aspects of internal process, customers, and employees (Kaplan \& Norton, 1993). Finally, BSC has been widely employed as a performance measurement tool. Based on previous related works, this study takes BSC as a performance measure to determine the corporate operating status. Furthermore, in order to represent the preference system of a corporate's management with domain knowledge, this study adopts SMARTER, with the results shown in Table 3. The performance score derived from BSC+SMARTER of the two highest ranking quintiles (top 40\%) is designated as those firms with superior operating performance, while the other corporates are designated as having inferior operating performance.

How to measure a model's forecasting quality in a reliable avenue is an attractive issue for academia and practitioners. The most commonly executed assessing criterion is the forecasting accuracy/error rate. However, forming a final decision merely relying on one assessing criterion is not trustworthy. Thus, this study advances to consider three other assessing criteria: precision, recall, and F-score. Each criterion is briefly described as follows (Peng, Wang, Kou, \& Shi, 2011). 
- Accuracy (ACC): $\mathrm{ACC}=(\mathrm{TN}+\mathrm{TP}) /(\mathrm{TP}+\mathrm{FP}+\mathrm{TN}+\mathrm{FN})$; it is the percentage of the correctly classified modules.

- Precision (PRE): $\mathrm{PRE}=\mathrm{TP} /(\mathrm{TP}+\mathrm{FP})$; it is the number of classified superior operating performance corporates that factually are superior operating performance corporates.

- Recall (REC): REC=TP/(TP+FN); it is the number of superior operating performance corporates that are correctly classified.

- F-score: F-Score $=2^{\star} \mathrm{PRE}^{\star} \mathrm{REC} /(\mathrm{PRE}+\mathrm{REC})$; it is the harmonic mean of recall and precision.

Table 3. The selected measures from BSC+MCDA

\begin{tabular}{|l|l|}
\hline \multicolumn{1}{|c|}{ Dimensions (Weight) } & \multicolumn{1}{c|}{ Measure (Weight) } \\
\hline \multirow{4}{*}{ Financial (0.46) } & Return on assets $(0.61)$ \\
\cline { 2 - 2 } & Sales growth rate $(0.11)$ \\
\cline { 2 - 2 } & Return on equities $(0.28)$ \\
\hline \multirow{2}{*}{ Customer (0.16) } & Sales return to total sales $(0.75)$ \\
\cline { 2 - 2 } & Market share to total market share $(0.25)$ \\
\hline \multirow{2}{*}{ Internal process (0.09) } & Sales to total assets $(0.75)$ \\
\hline \multirow{2}{*}{ Learning and innovation $(0.29)$} & Total sales to total employees $(0.25)$ \\
\hline & Research and development expenditure $(0.75)$ \\
\cline { 2 - 2 } & Higher education employees $(0.25)$ \\
\hline
\end{tabular}

Note: Weight was derived from SMARTER.

\subsection{The practical results and statistical examination}

In real-life research applications, one frequently encounters a dataset that is full of a tremendous amount of features. However, a great proportion of the features are redundant and irrelevant, resulting in poor forecasting performance of the target as well as increasing computational complexity. Because feature selection poses numerous merits, such as enhancing a model's forecasting performance, decreasing storage requirement, and strengthening data visualization (Dash \& Liu, 1997; Jensen \& Parthaláin, 2015), this study implements it to ameliorate the aforementioned obstacles. This study then conducts the selected features by FRST, which consists of financial information contents (F1 for "NI/TA", F2 for "WC/TA", F5 for "COGS/I", and F7 for "S/TA"), and CSR news report information contents (T2 for "ICSRPI-PB" and T3 for "ICSRPI-CS"). The NI/TA ratio describes how profitable a corporate is relative to its total assets and depicts how well management can utilize the corporate's assets to make a profit. The WC/TA ratio helps evaluate a corporate's ability to cover its short-term financial obligation by its assets and can give some insight about the corporate's liquidity ability. The COGS/I ratio describes how many times a corporate's inventory is sold and replaced over a time period and can give some insight about the corporate's profitability. The ratio S/TA is usually taken as an indicator to illustrate the efficiency of the corporate in generating revenue through its assets. The ICSRPI-PB ratio illustrates the relation between 
the product and the business. Cheng, Ioannou, and Serafeim (2014) indicated that the corporate with better CSR performance will face lower capital constraints, because better CSR performance is highly related to better stakeholder engagement, thus limiting the possibility of short-term opportunistic behaviors (Eccles, Ioannou, Serafeim, 2012). The ICSRPI-CS ratio represents the relationship between customers and suppliers. The survey done by Cone Corporate Citizen Study (CONE, 2004) shows that up to $80 \%$ of Americans are willing to support corporates associated with a socially response cause. The result shows that corporates with superior operating performance usually exhibit outstanding profitability, appropriate debt structure, efficient management, and well-constructed CSR relationship.

To test the usefulness of feature selection (FS), this study establishes three conditions: (1) Without feature selection, (2) Feature selection by RST, and (3) Feature selection by FRST. The result was represented in Table 4 . We can see that the model with feature selection performs better than the model without feature selection. This finding is in accordance with previous works who stated that feature selection not only can facilitate the model's forecasting performance, but also can reduce the storage requirement (Peng \& Fan, 2017; Zhang, Song, \& Gong, 2017; Costea, Ferrara, \& Şerban, 2017). Among all of the experiments, the model with FRST reaches the best forecasting quality. One of the possible reasons is that FRST not only preserves the merits of RST, but also prevent the weakness encountered by RST from information loss by data discretization. That is, original RST only can handle the discrete data. However, data undergoes the discretization process will lead to information loss. To overcome this challenge, the FRST was introduced.

Table 4. The forecasting results

\begin{tabular}{|l|c|c|c|}
\hline \multicolumn{4}{|c|}{ Model: LDA_PTSVM } \\
\hline \multicolumn{1}{|c|}{ Condition } & 1. Without FS & 2. FS by RST & 3. FS by FRST \\
\hline Accuracy & 63.8 & 79.2 & 85.88 \\
\hline Precision & 63.2 & 81.2 & 86.83 \\
\hline Recall & 63.97 & 78.08 & 81.32 \\
\hline F-score & 63.58 & 79.61 & 83.96 \\
\hline
\end{tabular}

To examine the effectiveness of CSR-related information contents, this study sets up three scenarios: (a) the model only with financial information contents (i.e., financial ratios), (b) the model only with CSR-related information contents (i.e., CSR textual information) and (c) the model with both financial information contents and CSR-related information contents (i.e., financial ratios and CSR textual information). A robust outcome does not happen by chance, and thus we perform the Wilcoxon signed-ranked test, which is a kind of non-parametric test, because a non-parametric test is much faster and more reliable than a parametric test without any prior assumptions (i.e., normal distribution) (Demšar, 2006).

Table 5 describes the results, which indicate that the model with financial ratios+CSRrelated information contents not only can increase forecasting performance, but also can eliminate biased outcome and errors. This finding is in accordance with Huang, Amy Zang, 
and Zheng (2014), who stated that textual content (i.e., CSR news reports) can provide incremental information beyond a quantitative summary by providing detailed information about many facets of a corporate. Furthermore, to ensure the robustness of the proposed hybrid model (i.e., LDA_PTSVM), we take it as a benchmark and compare it with three other kernel-based mechanisms. Due to some common advantages of easy design, superior generalization capability, strong tolerance to input noise, and good online learning ability, the radial basis functional neural network (RBFNN), relevance vector machine (RVM) and extreme learning machine (ELM) were taken to make a comparison.

Table 5. The forecasting results

\begin{tabular}{|c|c|c|c|}
\hline \multicolumn{4}{|c|}{ Model: LDA_PTSVM } \\
\hline \multirow{2}{*}{ Situation } & $\begin{array}{l}\text { (a) Only with financial } \\
\text { ratios }\end{array}$ & $\begin{array}{l}\text { (b) Only with CSR textual } \\
\text { information }\end{array}$ & $\begin{array}{l}\text { (c) With both financial ratios } \\
\text { and CSR textual information }\end{array}$ \\
\hline & \multicolumn{3}{|c|}{ Assessing criterion: ACC } \\
\hline Avg. & 74.74 & 18.62 & 85.88 \\
\hline \multicolumn{4}{|c|}{$\begin{array}{l}\text { Model scenario }_{(\mathrm{a})} \text { vs. Model scenario } \\
\text { (c) }\end{array}$} \\
\hline \multicolumn{4}{|c|}{ Assessing criterion: PRE } \\
\hline Avg. & 74.47 & 20.94 & 86.83 \\
\hline \multicolumn{4}{|c|}{$\begin{array}{l}\text { Model scenario }_{(a)} \text { vs. Model scenario } \\
\text { (c) }: \text { p-value }=0.000\left(^{(* *}\right) \\
\text { Model scenario }_{(\text {b) }} \text { vs. Model scenario }\left(\text { c) }: \text { p-value }=0.043{ }^{* *}\right)\end{array}$} \\
\hline \multicolumn{4}{|c|}{ Assessing criterion: REC } \\
\hline Avg. & 68.83 & 6.76 & 81.32 \\
\hline \multicolumn{4}{|c|}{ 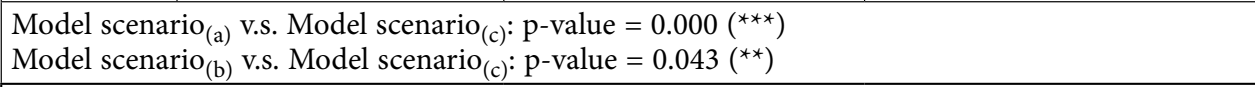 } \\
\hline \multicolumn{4}{|c|}{ Assessing criterion: F-Score } \\
\hline Avg. & 71.53 & 10.23 & 83.96 \\
\hline
\end{tabular}

Notes: ${ }^{*} \mathrm{p}$ value $<0.1 ;{ }^{* *} \mathrm{p}$ value $<0.05 ;{ }^{* *} \mathrm{p}$ value $<0.01$.

Table 6 reveals that the proposed LDA_PTSVM outperforms the other three mechanisms under all assessing criteria. The proposed LDA_PTSVM model, which is supported by real samples, can assist both internal and external stakeholders who must allocate their scarce economic resources to form financial decisions. Top executives or managers can consider the potential implications to form their future CSR policies as well as enhance their firm's growth potential to reach a 'win-win' situation. 
Table 6. The comparison results

\begin{tabular}{|c|c|c|}
\hline Benchmark & Comparison & $\mathrm{P}$-value \\
\hline \multicolumn{3}{|l|}{ Assessing criterion: Avg. ACC } \\
\hline \multirow{3}{*}{ LDA_PTSVM (85.88) } & RBFNN (70.38) & $0.042\left({ }^{* *}\right)$ \\
\hline & RVM (78.06) & $0.042\left(^{* *}\right)$ \\
\hline & ELM (79.58) & $0.043\left({ }^{* *}\right)$ \\
\hline \multicolumn{3}{|c|}{ Assessing criterion: Avg. PRE } \\
\hline \multirow{3}{*}{ LDA_PTSVM (86.83) } & RBFNN (67.97) & 0.043 (**) $^{*}$ \\
\hline & RVM (77.72) & $0.043\left(^{\star *}\right)$ \\
\hline & ELM (78.86) & $0.042\left({ }^{* *}\right)$ \\
\hline \multicolumn{3}{|c|}{ Assessing criterion: Avg. REC } \\
\hline \multirow{3}{*}{ LDA_PTSVM (81.32) } & RBFNN (64.41) & $0.043\left(^{* *}\right)$ \\
\hline & RVM (72.63) & $0.043\left(^{* *}\right)$ \\
\hline & ELM (74.63) & $\left.0.0433^{* *}\right)$ \\
\hline \multicolumn{3}{|c|}{ Assessing criterion: Avg. FS } \\
\hline \multirow{3}{*}{ LDA_PTSVM (83.96) } & RBFNN (66.14) & $0.043\left(^{* *}\right)$ \\
\hline & RVM (75.08) & $0.043\left({ }^{* *}\right)$ \\
\hline & ELM (76.68) & $0.043\left({ }^{* *}\right)$ \\
\hline
\end{tabular}

Notes: ${ }^{\star} \mathrm{p}$ value $<0.1 ;{ }^{\star *} \mathrm{p}$ value $<0.05$.

\subsection{Robustness test}

Most previous works reach a final conclusion that is only based on one pre-decided dataset, but it is intuitive that utilizing different datasets brings a higher chance of reaching different results. To solidify our research finding, we establish two different conditions: (1) Performance rank is decided by ROA, and (2) BSC's four perspectives are aggregated by the equal weight method. Figures 1-2 show the results. We can see that the proposed model still performs a satisfactory job in forecasting quality under two dissimilar conditions. Table 7 represents the model's discriminant capability, showing that the proposed model (BSC's per-

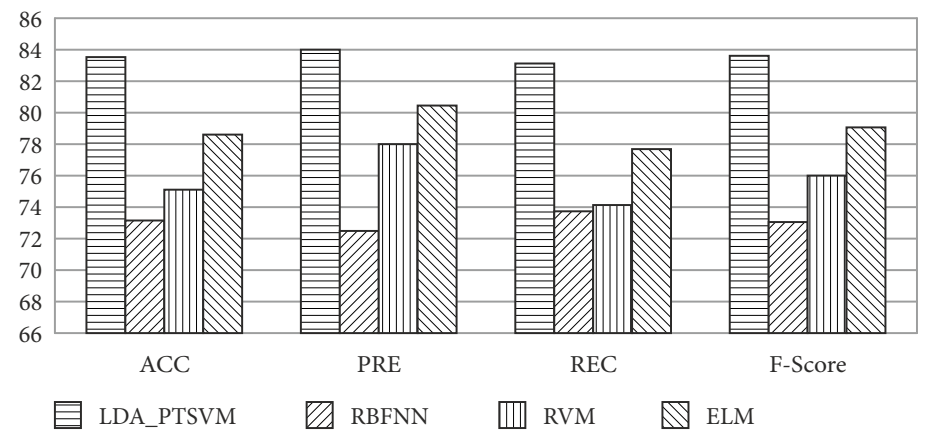

Figure 1. The comparison results in Condition 1 


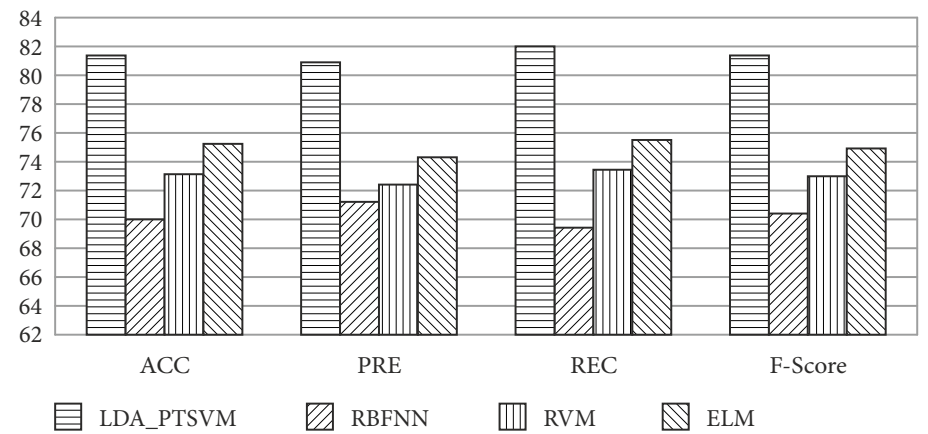

Figure 2. The comparison results in Condition 2

Table 7. The results in two models

\begin{tabular}{|l|c|c|}
\hline \multicolumn{1}{|c|}{ Model } & Mean & Variance \\
\hline Proposed model (BSC+ MCDA) & 0.743 & 0.32 \\
\hline Original model (BSC+ Equal weight) & 0.873 & 0.11 \\
\hline
\end{tabular}

spectives are aggregated by MCDA) is better than the original model (BSC's perspectives are aggregated by equal weight). In other words, given the tasks faced in reality, the multidimensional relationships among assessing criteria are of great concern in order to reach an appropriate and trustworthy decision.

\section{Conclusions and managerial implications}

The tremendous amounts of theoretical and empirical studies up to date identified no conclusive pattern in the relation between CSR and corporate operating performance. One of the main reasons for this absence of consensus is associated with measurement problems (Surroca et al., 2010). Given this concern, this study breaks down CSR news reports into numerous dimensions by LDA in order to provide a richer comprehension and conceptualization, concerning any relation between CSR and corporate operating performance.

As for the measurement of corporate operating performance, most related studies place considerable emphasis on accounting-based ratio analysis, such as employing ROI, ROA and ROS. However, the aforementioned assessing criteria are not trustworthy for depicting the full facet of a corporate's operations in a highly competitive environment. To ameliorate this obstacle, this study has executed BSC, which can offer a balanced assessment of the corporate's operations along with monetary (i.e., financial aspect) and non-monetary dimensions (i.e., operational, marketing and strategic aspects) as well as concentrate on both the shortterm and long-term objectives of a firm. Although BSC can yield overarching aspects of the corporate's operations for decision-makers, it still comes with some weaknesses: it often appears too general, and thus decision makers have no idea on how to incorporate the results into daily practice; or it seeks to translate a corporate's objectives into a coherent set of assess- 
ing criteria while minimizing information overload. This multidimensional problem of BSC can be handled by MCDA (Kou, Peng, \& Wang, 2014). Thus, SMARTER (which is a MCDA technique) was implemented herein to form a final and comprehensive decision system.

Compared to well-examined issues such as financial crisis prediction and credit rating prediction, research on corporate operating performance forecasting is quite rare, especially by considering financial information contents and CSR news report information contents at the same time. In order to fill this gap, this study proposes a novel hybrid model that takes quantitative (financial information) and qualitative (CSR news reports) information contents into consideration. By breaking down the CSR news reports into numerous dimensions, firm managers can attain deeper knowledge and can break down the barrier between CSR and corporate operating performance. In other words, the managers can realize the impact of each CSR dimension on corporate operating performance. They can then consider the potential implication and put much more concentration on those specific CSR dimensions that will enhance corporate operating performance and achieve a win-win situation. The introduced model, which is examined by real samples and has undergone a numerous statistical test, can assist decision makers in making reliable judgments. In addition, the result reveals that the proposed model is a promising alternative for corporate operating performance forecasting.

Several topics remain that could be discussed in future works. First, the forecasting model can be extended to a more synthesized or sophisticated architecture, such as gradient boosting, bagging, and stacking, to enhance the model's forecasting quality. Second, in addition to feature selection, other dimensionality reduction algorithms can be performed for a comparison, such as locally linear embedding (LLE) and isometric mapping (ISOMAP).

\section{Acknowledgement}

The authors would like to thank the Ministry of Science and Technology, Taiwan, R.O.C. for financially supporting this work under contracts No.106-2410-H-034-046-MY2, and No. 106-2410-H-034-011-MY3.

\section{References}

Altman, E. I. (1968). Financial ratios, discriminant analysis and the prediction of corporate bankruptcy. Journal of Finance, 23, 589-609. https://doi.org/10.1111/j.1540-6261.1968.tb00843.x

Asmild, M., \& Zhu, M. (2016). Controlling for the use of extreme weights in bank efficiency assessments during the financial crisis. European Journal of Operational Research, 251, 999-1015. https://doi.org/10.1016/j.ejor.2015.12.021

Barcos, L., Barroso, A., Surroca, J., \& J. Tribó, A. (2013). Corporate social responsibility and inventory policy. International Journal of Production Economics, 143, 580-588. https://doi.org/10.1016/j.ijpe.2012.04.005

Barnard, K., Duygulu, P., de Freitas, N., Forsyth, D., Blei, D., \& Jordan, M. (2003). Matching words and pictures. Journal of Machine Learning Research, 3, 1107-1135.

Beaver, W. H. (1996). Financial ratios as predictors of failure. Journal of Accounting Research, 4, 71-111. https://doi.org/10.2307/2490171 
Buncic, D., \& Piras, G. D. (2016). Heterogeneous agents, the financial crisis and exchange rate predictability. Journal of International Money and Finance, 60, 313-359.

https://doi.org/10.1016/j.jimonfin.2015.09.006

Blei, D., Ng, A., \& Jordan, M. (2003). Latent Dirichlet allocation. Journal of Machine Learning Research, 3, 993-1022.

Bohl, M. T., Michaelis, P., \& Siklos, P. L. (2016). Austerity and recovery: exchange rate regime choice, economic growth, and financial crises. Economic Modelling, 53, 195-207. https://doi.org/10.1016/j.econmod.2015.11.017

Carroll, A. B. (1979). A three-dimensional model of corporate performance. Academy of Management Review, 4, 497-505. https://doi.org/10.5465/amr.1979.4498296

Carroll, A. B. (1991). The pyramid of corporate social responsibility: toward the moral management of organizational stakeholders. Business Horizons, 34, 39-48.

https://doi.org/10.1016/0007-6813(91)90005-G

Carroll, A. B. (1998). The four faces of corporate citizenship. Business and Society Review, 100, 1-7. https://doi.org/10.1111/0045-3609.00008

Cavaco, S., \& Crifo, P. (2014). CSR and financial performance: complementarity between environmental, social and business behaviours. Applied Economics, 46, 3323-3338.

https://doi.org/10.1080/00036846.2014.927572

Chong, Y. Q., Wang, B. T., Gladys, L. Y., \& Cheong, S. A. (2014). Diversified firms on dynamical supply chain cope with financial crisis better. International Journal of Production Economics, 150, 239-245. https://doi.org/10.1016/j.ijpe.2013.12.030

Cheng, B., Ioannou, I., \& Serafeim, G. (2014). Corporate social responsibility and access to finance. Strategic Management Journal, 35, 1-23. https://doi.org/10.1002/smj.2131

Chen, X., Yang, J., Ye, Q., \& Liang, J. (2011). Recursive projection twin support vector machine via within-class variance minimization. Pattern Recognition, 44, 2643-2655. https://doi.org/10.1016/j.patcog.2011.03.001

Crifo, P., Diaye, M. A., \& Pekovic, S. (2016). CSR related management practices and firm performance: an empirical analysis of the quantity-quality trade-off on French data. International Journal of Production Economics, 171, 405-416. https://doi.org/10.1016/j.ijpe.2014.12.019

Crouch, C. J., \& Yang, B. (1992). Experiments in automatic statistical thesaurus construction. Proceeding SIGIR '92 Proceedings of the 15th annual international ACM SIGIR conference on Research and development in information retrieval (pp. 77-88). https://doi.org/10.1145/133160.133180

Costea, A., Ferrara, M., \& Şerban, F. (2017). An integrated two-stage methodology for optimising the accuracy of performance classification models. Technological and Economic Development of Economy, 23, 111-139. https://doi.org/10.3846/20294913.2016.1213196

CONE (2004). Cone Corporate Citizenship Study. Retrieved from http://mycoachescorner.com/media/ 2004ConeCorporateCitizenshipStudy.pdf

Commission of the European Communities (2001). Green Paper: Promoting a European framework for corporate social responsibility. Retrieved from https://www.iisd.org/business/issues/eu_green_paper. aspx

Dash, M., \& Liu, H. (1997). Feature selection for classification. Intelligent Data Analysis, 1, 131-156. https://doi.org/10.1016/S1088-467X(97)00008-5

Demšar, J. (2006). Statistical comparisons of classifiers over multiple data sets. Journal of Machine Learning Research, 7, 1-30.

Ding, S., \& Hua, X. (2014). Recursive least squares projection twin support vector machines for nonlinear classification. Neurocomputing, 130, 3-9. https://doi.org/10.1016/j.neucom.2013.02.046 
Eccles, R., Ioannou, I., \& Serafeim, G. (2012). The impact of a corporate culture of sustainability on corporate behavior and performance. Harvard Business School Working Paper.

Fatma, M., Rahman, Z., \& Khan, I. (2016). Measuring consumer perception of CSR in tourism industry: scale development and validation. Journal of Hospitality and Tourism Management, 27, 39-48. https://doi.org/10.1016/j.jhtm.2016.03.002

Fatma, M., \& Rahman, Z. (2016). The CSR's influence on customer responses in Indian banking sector. Journal of Retailing and Consumer Services, 29, 49-57. https://doi.org/10.1016/j.jretconser.2015.11.008

Freeman, R. (1984). Strategic management: a stakeholder perspective. Piman: Boston, MA.

Geng, R., Bose, I., \& Chen, X. (2015). Prediction of financial distress: an empirical study of listed Chinese companies using data mining. European Journal of Operational Research, 241, 236-247. https://doi.org/10.1016/j.ejor.2014.08.016

Grigoroudis, E., Orfanoudaki, E., \& Zopounidis, C. (2012). Strategic performance measurement in a healthcare organisation: a multiple criteria approach based on balanced scorecard. Omega, 40, 104119. https://doi.org/10.1016/j.omega.2011.04.001

Griffiths, T. L., \& Steyvers, M. (2004). Finding scientific topics. Proceedings of the National Academy of Science, 101, 5228-5235. https://doi.org/10.1073/pnas.0307752101

Hillman, A. J., \& Keim, G. D. (2001). Shareholder value, stakeholder management, and social issues: what's the bottom line?. Strategic Management Journal, 22, 125-139. https://doi.org/10.1002/1097-0266(200101)22:2<125::AID-SMJ150>3.0.CO;2-H

Huang, H., Amy Zang Y., \& Zheng, R. (2014). Evidence on the information content of text in analyst reports. Accounting Review, 89, 2151-2180. https://doi.org/10.2308/accr-50833

Hull, C. E., \& Rothenberg, S. (2008). Firm performance: the interactions of corporate social performance with innovation and industry differentiation. Strategic Management Journal, 29, 781-789. https://doi.org/10.1002/smj.675

Hyun, J. (2016). Financial crises and the evolution of credit reallocation: evidence from Korea. Economic Modelling, 56, 25-34. https://doi.org/10.1016/j.econmod.2016.03.019

Isaksson, R., \& Steimle, U. (2009). What does GRI - reporting tell us about corporate sustainability?. The TQM Journal, 21, 168-181. https://doi.org/10.1108/17542730910938155

International Organization for Standardization. (2010). ISO 26000 - Social responsibility. Retrieved from https://www.iso.org/iso-26000-social-responsibility.html

Jayadeva, Khemchandani, R., \& Chandra S. (2007). Twin support vector machine for pattern classification. IEEE Transactions on Pattern Analysis and Machine Intelligence, 29, 905-910. https://doi.org/10.1109/TPAMI.2007.1068

Jensen, R., \& Parthaláin, N. M. (2015). Towards scalable fuzzy-rough feature selection. Information Sciences, 323, 1-15. https://doi.org/10.1016/j.ins.2015.06.025

Jones, F. L. (1987). Current techniques in bankruptcy prediction. Journal of Accounting Literature, 6, 131-164.

Kapstein, E. (2001). The corporate ethics crusade. Foreign Affairs, 80, 105-119. https://doi.org/10.2307/20050254

Kaplan, R. S., \& Norton, D. P. (1992). The balanced scorecard measures that drive performance. Harvard Business Review, 70, 71-79.

Kaplan, R. S., \& Norton, D. P. (1993). Putting the balanced scorecard to work. Harvard Business Review, 71, 134-147.

Kumar, M. A., \& Gopal, M. (2009). Least squares twin support vector machines for pattern classification. Expert Systems with Applications, 36, 7535-7543. https://doi.org/10.1016/j.eswa.2008.09.066 
Kumar, M. A., Khemchandani, R., Gopal, M., \& Chandra, S. (2010). Knowledge based least squares twin support vector machines. Information Sciences, 180, 4606-4618. https://doi.org/10.1016/j.ins.2010.07.034

Kou, G., Peng, Y., Wang, G. (2014). Evaluation of clustering algorithms for financial risk analysis using MCDM methods. Information Sciences, 275, 1-12. https://doi.org/10.1016/j.ins.2014.02.137

Li, F. (2010). The information content of forward-looking statements in corporate filings - a naïve Bayesian machine learning approach. Journal of Accounting Research, 48, 1049-1102. https://doi.org/10.1111/j.1475-679X.2010.00382.x

Magni, C. A. (2015). Investment, financing and the role of ROA and WACC in value creation. European Journal of Operational Research, 244, 855-866. https://doi.org/10.1016/j.ejor.2015.02.010

Malmi, T. (2001). Balanced scorecards in Finnish companies: a research note. Management Accounting Research, 12, 207-220. https://doi.org/10.1006/mare.2000.0154

Mollah, S., Quoreshi, A. M. M. S., \& Zafirov, G. (2016). Equity market contagion during global financial and Eurozone crises: evidence from a dynamic correlation analysis. Journal of International Financial Markets, Institutions and Money, 41, 151-167. https://doi.org/10.1016/j.intfin.2015.12.010

Mohr, L. A., Webb, D. J., \& Harris, K. E. (2001). Do consumers expect companies to be socially responsible? The impact of corporate social responsibility on buying behavior. Journal of Consumer Affairs, 35, 45-72. https://doi.org/10.1111/j.1745-6606.2001.tb00102.x

Navarro, P. (1988). Why do corporations give to charity?. Journal of Business, 61, 65-93. https://doi.org/10.1086/296420

Pantalone, C. C., \& Platt, M. B. (1987). Predicting failure of savings and loan associations. Real Estate Economics, 15, 46-64. https://doi.org/10.1111/1540-6229.00418

Peng, Y., Wang, G., Kou, G., \& Shi, Y. (2011). An empirical study of classification algorithm evaluation for financial risk prediction. Applied Soft Computing, 11, 2906-2915.

https://doi.org/10.1016/j.asoc.2010.11.028

Peng, H., \& Fan, Y. (2017). Feature selection by optimizing a lower bound of conditional mutual information. Information Sciences, 418-419, 652-667. https://doi.org/10.1016/j.ins.2017.08.036

Rodriguez-Fernandez, M. (2016). Social responsibility and financial performance: the role of good corporate governance. BRQ Business Research Quarterly, 19, 137-151.

https://doi.org/10.1016/j.brq.2015.08.001

Shirata, Cindy Y., Takeuchi, H., Ogino, S., \& Watanabe, H. (2011). Extracting key phrases as predictors of corporate bankruptcy: empirical analysis of annual reports by text mining. Journal of Emerging Technologies in Accounting, 8, 31-44. https://doi.org/10.2308/jeta-10182

Sen, S., \& Bhattacharya, C. B. (2001). Does doing good always lead to doing better? Consumer reactions to corporate social responsibility. Journal of Marketing Research, 38, 225-243.

https://doi.org/10.1509/jmkr.38.2.225.18838

Shao, Y. H., Zhang, C. H., Wang, X. B., \& Deng, N. Y. (2011). Improvements on Twin Support Vector Machines. IEEE Transactions on Neural Networks, 22, 962-968.

https://doi.org/10.1109/TNN.2011.2130540

Shao, Y. H., Wang, Z., Chen, W. J., \& Deng, N. Y. (2013). A regularization for the projection twin support vector machine. Knowledge-Based Systems, 37, 203-210.

https://doi.org/10.1016/j.knosys.2012.08.001

Shao, Y. H., Chen, W. J., Wang, Z., Li, C. N., \& Deng, N. Y. (2015). Weighted linear loss twin support vector machine for large-scale classification. Knowledge-Based Systems, 73, 276-288. https://doi.org/10.1016/j.knosys.2014.10.011

Shao, Y. H., \& Deng, N. Y. (2012). A coordinate descent margin based-twin support vector machine for classification. Neural Networks, 25, 114-121. https://doi.org/10.1016/j.neunet.2011.08.003 
Surroca, J., Tribo, J. A., \& Waddock, S. (2010). Corporate responsibility and financial performance: the role of intangible resources. Strategic Management Journal, 31, 463-490. https://doi.org/10.1002/smj.820

$\mathrm{Xu}, \mathrm{X} .$, \& Wang, Y. (2009). Financial failure prediction using efficiency as a predictor. Expert Systems with Applications, 36, 366-373. https://doi.org/10.1016/j.eswa.2007.09.040

Zhu, Q., Liu, J., \& Lai, K. (2016). Corporate social responsibility practices and performance improvement among Chinese national state-owned enterprises. International Journal of Production Economics, 171, 417-426. https://doi.org/10.1016/j.ijpe.2015.08.005

Zmijewski, M. E. (1984). Methodological issues related to the estimation of financial distress prediction models. Journal of Accounting Research, 22, 59-82. https://doi.org/10.2307/2490859

Zhang, Y., Song, X., \& Gong, D. (2017). A return-cost-based binary firefly algorithm for feature selection. Information Sciences, 418-419, 561-574. https://doi.org/10.1016/j.ins.2017.08.047 